\title{
Frédéric Houbert, Practical Guide to Legal Translation
}

Paris : Maison du dictionnaire, 2005

\section{Rosalind Greenstein}

\section{(2) OpenEdition}

Journals

Édition électronique

URL : http://journals.openedition.org/asp/3600

DOI : $10.4000 /$ asp.3600

ISBN : 978-2-8218-0410-4

ISSN : 2108-6354

\section{Éditeur}

Groupe d'étude et de recherche en anglais de spécialité

\section{Édition imprimée}

Date de publication : 1 novembre 2009

Pagination : 134-135

ISSN : 1246-8185

\section{Référence électronique}

Rosalind Greenstein, «Frédéric Houbert, Practical Guide to Legal Translation », ASp [En ligne], 56 | 2009, mis en ligne le 06 décembre 2009, consulté le 02 novembre 2020. URL : http://

journals.openedition.org/asp/3600 ; DOI : https://doi.org/10.4000/asp.3600

Ce document a été généré automatiquement le 2 novembre 2020.

Tous droits réservés 


\section{Frédéric Houbert, Practical Guide to Legal Translation}

Paris : Maison du dictionnaire, 2005

Rosalind Greenstein

\section{RÉFÉRENCE}

Houbert, Frédéric. 2005. Practical Guide to Legal Translation. Paris : Maison du dictionnaire. ISBN 2-85608-186-X. 283 p. 
Les quatre ouvrages présentés ici ont en commun le fait de traiter de la langue du droit, de manière différente et complémentaire et en visant des publics hétérogènes. Bien sûr, le contenu des livres ainsi que leur lectorat peuvent se recouper, d'où la question suivante: comment un lecteur potentiel va-t-il faire son choix? Tout d'abord, en regardant le titre; ensuite, en lisant la quatrième de couverture. Et c'est là que le bât blesse. Car soit par ignorance, soit parce que confrontés à des impératifs commerciaux mal maîtrisés, les éditeurs (à moins que ce ne soit les auteurs) donnent souvent l'impression que le livre s'adresse à plusieurs publics à la fois, au risque de décevoir les lecteurs qui, par conséquent, hésiteront à acheter d'autres livres à l'avenir. Quels sont, donc, les quatre ouvrages et comment peuvent-ils répondre aux besoins et aux attentes de la communauté des anglicistes de spécialité?

2 Toute personne se fiant aux première et quatrième de couverture de Practical Guide to Legal Translation serait pardonnée de penser que ce livre est rédigé en anglais. Mais il suffit de lire la précision « anglais-français » à la page de garde pour comprendre qu'en réalité l'ouvrage est rédigé en français car destiné à tous ceux qui devront, un jour, comprendre un texte juridique en anglais et / ou surtout le traduire en français. Il est divisé en trois grandes parties qui se complètent: 1) Caractéristiques de la langue juridique anglaise et française et spécificités de la traduction juridique ; 2 ) Culture et traduction juridique ; 3) Textes traduits et annotés.

3 La première partie, qui ne prétend pas à l'exhaustivité, permet au lecteur de se familiariser avec certaines caractéristiques et spécificités du langage juridique et leurs conséquences sur la bonne compréhension et donc la bonne traduction d'un texte : les locutions latines, la polysémie, l'ambiguïté, les auxiliaires modaux, les adverbes composés, les archaïsmes... L'auteur passe de l'analyse à l'anecdote, illustre non sans humour son propos avec des exemples bien choisis et, là où c'est possible, complète la présentation par des exercices d'application. Le seul bémol réside dans l'absence de corrigés, en fin de chapitre ou en fin de livre, pour le lecteur qui travaille seul.

deuxième partie, courte, met l'accent sur la relation entre langue et culture, aspect trop souvent négligé par ceux qui pensent, naïvement, qu'il suffit de prendre des glossaires bi- ou multilingues pour trouver la solution aux problèmes de traduction. Mais, de tous les domaines spécialisés, le droit est celui où la relation entre langue et culture est la plus forte et où la « chose » décrite n'existe pas en dehors de la langue qui permet de l'exprimer, justement. L'auteur prend une étude de cas - un article intitulé Rule of judges - pour illustrer son propos, avant de réfléchir au problème de la traduction des titres de films inspirés d'expressions juridiques et à l'apport de la lexicologie dans le travail du traducteur juridique. 
5 La troisième partie, enfin, propose seize textes de types très différents, allant de la Convention de Hambourg 1978 (sur le droit commercial international) à un arrêt de la Cour de justice des Communautés européennes, en passant par divers contrats, des statuts d'une société et un jugement d'une district court américaine. L'original et la traduction sont présentés en regard, ce qui permet une lecture et une comparaison aisées des deux textes.

6 Outre un index des termes et expressions juridiques en anglais, on trouve à la fin du livre un glossaire des termes techniques français utilisés dans les commentaires de l'auteur tout au long de son ouvrage, ainsi qu'une bibliographie.

\section{AUTEURS}

ROSALIND GREENSTEIN

Université Paris 1 Panthéon-Sorbonne 